\title{
Studies on mass transfer of europium(III) in micro-channels using a micro Laser Induced Fluorescence technique
}

\author{
Panagiota Angeli, Dimitrios Tsaoulidis, Weheliye Hashi Weheliye
}

Authors in alphabetical order

Chemical Engineering Department, University College London, WClE 7JE, London, UK

Correspondingauthors:p.angeli@ucl.ac.uk; d.tsaoulidis@ucl.ac.uk; weheliye.weheliye.10@ucl.ac.uk

\begin{abstract}
The mass transfer of europium(III) from an aqueous to an organic phase was studied in a quartz microchannel (internal diameter of $200 \mu \mathrm{m}$ ) using a novel micro Laser Induced Fluorescence (micro-LIF) technique. Europium(III) was extracted from a $1 \mathrm{M}$ nitric acid solution into an organic solution of TBP(1.2M)/CMPO(0.2M) in Exxsol D80. For the flow rates investigated plug flow was established. An experimental and data processing methodology was developed to calculate concentration profiles from the fluorescing light intensity profiles in both phases at different locations along the microchannel. In particular, the effect that the high light intensity of the organic phase has on the measurements in the aqueous phase was taken into account. Mass transfer was found to be significant in the beginning of the channel close to the inlet ( $1 \mathrm{~mm}$ distance) with extraction percentages varying between 20 to $40 \%$ depending on the total flow rate. High extraction efficiency $(\sim 80 \%)$ was achieved at short residence times (in the first $6 \mathrm{~s}$ ), while the overall volumetric mass transfer coefficients varied between 0.05 and $3.3 \mathrm{~s}^{-1}$.
\end{abstract}

Keywords: Mass transfer, micro-LIF, Europium(III), Microchannel, Liquid-Liquid

\section{Introduction}

Microfluidic devices are very powerful tools for the development of intensified, efficient, resource saving, and environmental-friendly processes. The small length scales offer, among others, high surface-to-volume ratio, enhanced heat/mass rates, narrow drop size and residence time distributions, and safe operation $[1,2]$. In recent years, there have been increased efforts to translate studies from microfluidic devices into practical applications in many areas including, hydrometallurgy for efficient separation and enrichment of metal ions, biotechnology for 
cell manipulation, analytical chemistry ( $\mu$-TAS systems) for DNA and protein purification, and pharmaceuticals for drug delivery [3-7].

From the many different patterns that can form during liquid-liquid flows in small channels, segmented (plug flow) is the preferred one for applications where high mass transfer rates are important, such as liquid-liquid extractions [8-10]. In this pattern, one phase forms dispersed plugs with diameter larger than the channel size, whilst the other, continuous, phase (slugs) surrounds the plugs and separates them from each other and from the wall. The large interfacial area favours mass transfer, while the well-defined and regular flow geometry and the laminar flow fields allow precise modelling and characterization of the small scale units [11, 12]. Mass transfer coefficients of up to two or three orders of magnitude higher than in conventional contactors have been found [13, 14].

One of the many areas that small scale units can be applied is in the extraction of lanthanides [15]. Lanthanides, such as europium(III), play a growing role in modern society, and find applications in LEDs, laser technology, luminescent lighting, and as industrial catalysts [16]. Scarcity on natural resources means that the large quantities of lanthanides present in electronic waste such as spent fluorescent lamps, computer monitor scraps and colour TV tubes need to be recycled. Lanthanides also have a range of nuclear applications; they have been used in control rods to regulate nuclear reactors because of their properties to absorb neutrons. In addition, they have been used as structural components in reactors, as well as shielding materials [17]. Liquid-liquid extraction is commonly used for the recovery of these metals, but current technologies are based on process units, such as mixers/settlers and counter-current columns that are large and not well characterised [18]. In a recent study small scale extractors were used for the separation of europium(III) where higher mass transfer coefficients up to 0.07 $\mathrm{s}^{-1}$ were found [15]. Mass transfer was monitored by analysing samples at the end of the micro-units using UVVis.

Despite significant progress on velocity field measurements in small channels using particle image velocimetry (PIV) techniques [19-22], concentration profiles are less well investigated. Mixing patterns have been obtained from the measurement of fluorescence intensity of passive scalars with micro Laser Induced Fluorescence (microLIF) [23, 24]. To date, concentration profiles and mass transfer within microchannels have mainly been studied via numerical simulations $[25,26]$ partly because of the experimental difficulties encountered in obtaining detailed measurements of the concentration. The study by Bai et al. (2016) [27] is the only one where micro-LIF is used 
to investigate the mass transfer of water into ionic liquid in different microchannel inlets using Rhodamine $6 \mathrm{G}$ as the model solute.

The mass transfer of europium(III) from an aqueous to an organic phase in a microchannel extractor is studied here using a novel micro-LIF technique. This is the first time that the concentration profiles of the transferring species are monitored along a microchannel. The development of the technique and of appropriate data processing methodologies for the evaluation of the concentration profiles in both phases are then discussed; in particular, a methodology is presented for alleviating the effects of the high intensity light from the organic phase on the concentration measurements in the aqueous phase. The experimental results are then presented for a range of conditions and positions along the channel. From the concentration profiles the amount of europium extracted and overall mass transfer coefficients are calculated

\section{Materials and experimental setup}

The continuous extraction of europium(III) from aqueous nitric acid solutions (1 M) into an organic solution $\mathrm{D} 80 / \mathrm{TBP}(1.2 \mathrm{M}) / \mathrm{CMPO}(0.2 \mathrm{M})$ was investigated in a circular quartz microchannel of internal diameter (ID) 200 $\mu \mathrm{m}$ at different positions $\left(\mathrm{P}_{\mathrm{i}}\right)$ along the channel, as shown in Figure 1. The inlet was a T-junction where each side channel had the same diameter as the main one. The fluids were chosen to simulate the TRUEX (TRansUranic EXtraction) extraction process in nuclear waste management for the separation of transuranic elements from lanthanides.

a)

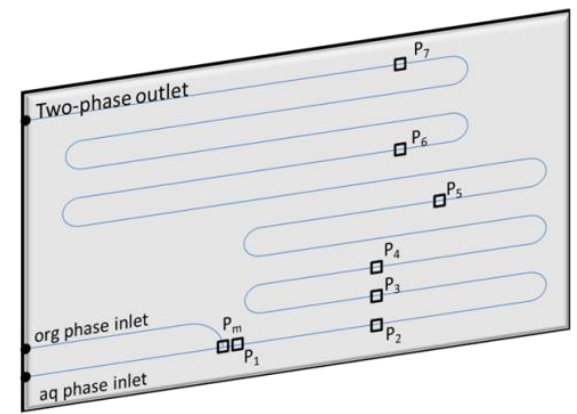

b)

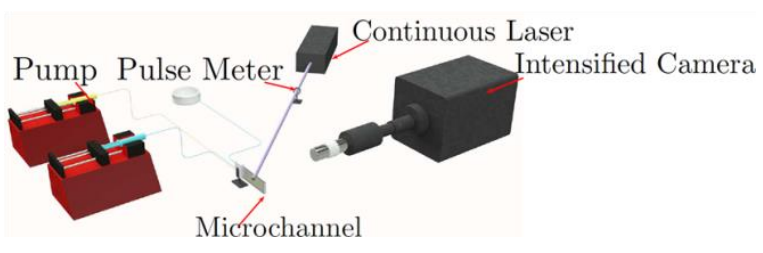

Fig. 1. (a) Schematic representation of the $200 \mu \mathrm{m}$ ID microchannel (b) Sketch of the experimental setup for the LIF measurements. 
The tri-n-butylphosphate (TBP), which acts as a modifier to prevent third phase formation at the interface, was purchased from Sigma-Aldrich. The n-octyl(pheny1)-N,N-diisobutylcarbamoylmethylphosphine oxide (CMPO) was used as extractant and obtained from Carbosynth Limited. The aliphatic hydrocarbon solvent Exxsol D80 was purchased from ExxonMobil. The fluids were fed into the side channels using high-precision continuous syringe pumps (Harvard PHD Ultra), one for each phase. The aqueous phase entered from the T-junction channel that was at the same axis as the main one while the organic phase entered from the perpendicular side channel. The operating conditions were chosen to give plug flow and are shown in Table 1. For the two-phase system used in this work (see Table 2), the organic solution (D80/TBP/CMPO) formed the dispersed plugs, while the aqueous solution $\left(\mathrm{HNO}_{3(\mathrm{aq})} / \mathrm{Eu}(\mathrm{III})\right)$ was the continuous phase. The viscosity of the organic phase was measured experimentally using a Modular Compact Rheometer (MCR302) by Anton Paar. Although the two phases are immiscible, small amounts of each phase can still be dissolved into the opposite one, which will affect the accuracy of the LIF technique. Thus, in the experiments the two phases were pre-saturated. Equilibrium extractions were also carried out at room temperature by stirring the two phases overnight before separating them. The concentration of the europium(III) for the equilibrium experiments was measured in each phase using a UV-Vis spectrometer (USB2000+, Ocean Optics) to validate the approach.

Table 1. Operating conditions.

\begin{tabular}{|lc|}
\hline Temperature, $\mathrm{T}$ & $22 \pm 1^{\circ} \mathrm{C}$ \\
Organic (aqueous) phase flow rate, $\mathrm{Q}_{\mathrm{org}}\left(\mathrm{Q}_{\mathrm{aq}}\right)$ & $1-5 \mu \mathrm{L} / \mathrm{min}$ \\
Organic (aqueous) superficial velocity, $\mathrm{u}_{\mathrm{org}}\left(\mathrm{u}_{\mathrm{aq}}\right)$ & $0.53-2.65 \mathrm{~mm} / \mathrm{s}$ \\
Flow rate ratio, $\mathrm{r}\left(\mathrm{Q}_{\mathrm{org}} / \mathrm{Q}_{\mathrm{aq}}\right)$ & $0.5-1$ \\
Reactor length, $\mathrm{L}_{\mathrm{r}}$ & $27.2 \mathrm{~cm}$ \\
Initial Eu(III) concentration in the aqueous phase, $\mathrm{C}_{\mathrm{aq}, \mathrm{t} 0}$ & $6 \mathrm{mg} / \mathrm{mL}$ \\
\hline
\end{tabular}


Table 2. Fluid properties.

\begin{tabular}{|c|c|c|}
\hline \multirow{2}{*}{ Property } & \multicolumn{2}{|c|}{ Chemicals } \\
\cline { 2 - 3 } & Exxsol D80/TBP(1.2 M)/CMPO(0.2 M) & \multicolumn{2}{|c|}{ HNO $_{3}(\mathbf{1}$ M) } \\
\hline Density $\left(\mathrm{kg} \mathrm{m}^{-3}\right)$ & ${ }^{\mathrm{a}} 852$ & ${ }^{\mathrm{a}} 1079$ \\
\hline Viscosity $\left(\mathrm{kg} \mathrm{m}^{-1} \mathrm{~s}^{-1}\right)$ & ${ }^{\mathrm{b}} 2.5 \cdot 10^{-3}$ & ${ }^{\mathrm{a}} 0.994 \cdot 10^{-3}$ \\
\hline
\end{tabular}

a - Values as given by the manufacturer. b- Values as measured in the UCL laboratory

\section{Development of $\mu$-LIF methodology}

\subsection{Laser apparatus characteristics}

The micro-LIF system used consisted of a continuous diode laser (Vortran Laser), pulse meter (TSI instruments), and a 12-bit intensified camera (Sensicam, PCO). The laser has an output power of $100 \mathrm{~mW}$ with a wavelength of $396 \mathrm{~nm}$ and illuminated the microchannel from a $45^{\circ}$ angle (volume illumination; see Fig. 1). A spherical lens was placed in front of the laser unit to produce a tight focal spot. The laser beam excited the europium(III) which has peak absorption and emission wavelengths of $395 \mathrm{~nm}$ and $610 \mathrm{~nm}$, respectively. No photo-bleaching was observed, and the intensity of the europium(III) was found not to be sensitive to temperature variations. The orange emission from the europium(III) was detected by the 12-bit intensified camera, which implies that the LIF measurements were obtained with a 4095 grey scale -range. The intensified camera was equipped with an optical train (TSI instruments) and long focal distance microscope lens. This configuration provided $\times 40$ magnification and spatial resolution of $0.85 \mu \mathrm{m} / \mathrm{pixel}$. The focal plane was placed in the center of the channel and the depth of field was approximately $3 \mu \mathrm{m}$ for the specification of the microscope lens [28]. An orange filter with a cut-off wavelength of $570 \mathrm{~nm}$ was put in front of the camera lens to minimize reflections from the microchannel walls. Images were obtained at a frequency of $14.5 \mathrm{~Hz}$ and were synchronized with a laser pulse meter that was constantly checked throughout the experiments for laser energy fluctuations, which can potentially affect the concentration measurements. The analysis of the data indicated that the fluctuations were less than $1 \%$ and had negligible effect on the concentration measurements.

\subsection{Image processing procedure}

Initially, the calibration curves correlating the fluorescence intensity and europium(III) concentration in both phases were investigated. Different solutions with concentrations of europium(III) ranging from 1 to $6 \mathrm{mg} / \mathrm{mL}$ 
dissolved in both phases were prepared. This concentration range was chosen to avoid camera scale saturation in the organic phase. In addition within this range, there is a balance in the fluorescent light emitted from the organic and from the aqueous phases, and LIF measurements can be carried out in both phases. Subsequently, each phase with a certain concentration of europium(III) was introduced in the microchannel and the corresponding fluorescence intensity was recorded. The average grey scale over the whole channel was calculated from the recorded images and plotted against the corresponding concentration as shown in Fig 2 . The intensity values shown in Fig 2 where normalised with the maximum grey scale of the camera which is 4095 .

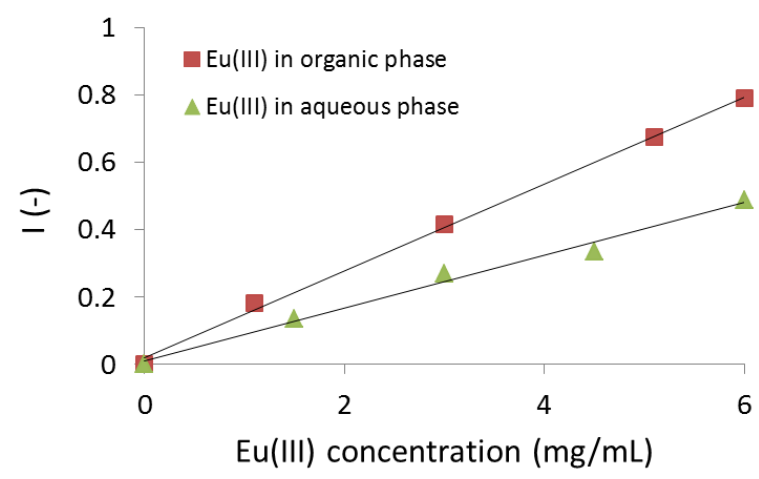

Fig. 2. Calibration curve of the normalized europium fluorescence intensity at increasing concentrations of europium in both phases.

As can be seen, there is a linear relationship between normalised intensity and concentration of europium(III) for both phases. For the rest of the study, images are normalized according to Eq. (1):

$I_{n}=\frac{I-I_{0}}{I_{\text {ref }}-I_{0}}$

where the index $\mathrm{n}$ denotes the phase of interest (i.e. org or aq) and $\mathrm{I}_{\mathrm{O}} \mathrm{I}_{\mathrm{o}}$ and $\mathrm{I}_{\text {ref }}$ are the raw, background and reference images, respectively. The image obtained for $6 \mathrm{mg} / \mathrm{mL}$ of europium(III) in the aqueous or the organic phase is employed as the reference image, $I_{\mathrm{ref}}$, for the corresponding phase. The image obtained for the pure aqueous or organic phase (without any europium(III)) is employed as the background image, $\mathrm{I}_{0}$, for the corresponding phase. Experiments were carried out at seven positions along the channel (P1-P7, see Fig. 1a). For each of the chosen positions, the light intensity in each phase was averaged over many plugs or slugs. However, the plugs (or slugs) were not always in the same location in the captured images (see Fig. 3a). An in-house preprocessing routine was developed to identify the moving plugs (or slugs) in the images and translate them to the 
same reference frame for the phase averaging (see Fig. 3a). The average concentration, $I^{*}$, in the plug or slug was then calculated as follows

$\mathrm{I}_{\mathrm{n}}^{*}=\frac{1}{\mathrm{~A}} \oint \mathrm{I}_{\mathrm{n}} \mathrm{dA}$

where $\mathrm{A}$ is the area of the plug (or slugs). To check whether the location of the plug (or slug) in the image affected the light intensity, the average intensities, $\mathrm{I}_{\mathrm{org}}^{*}$, in the plugs are plotted in Fig. $3 \mathrm{~b}$ for different $\Delta \mathrm{x}$, where $\Delta \mathrm{x}$ is the distance between the tip of the reference plug $\left(\mathrm{x}_{1}\right)$ and of the measured plug $\left(\mathrm{x}_{2}\right)$ in the raw image. It can be seen that for both positions $\mathrm{P} 1$ and $\mathrm{P} 6, \mathrm{I}_{\mathrm{org}}^{*}$ remains almost constant at different $\Delta \mathrm{x} / \mathrm{d}$ over the length of one channel diameter. Therefore, the images obtained from the micro-LIF can be phase-averaged for plugs that are a channel diameter in front or at the back of the reference plug in each location. For the final results 30 images were averaged.

a)

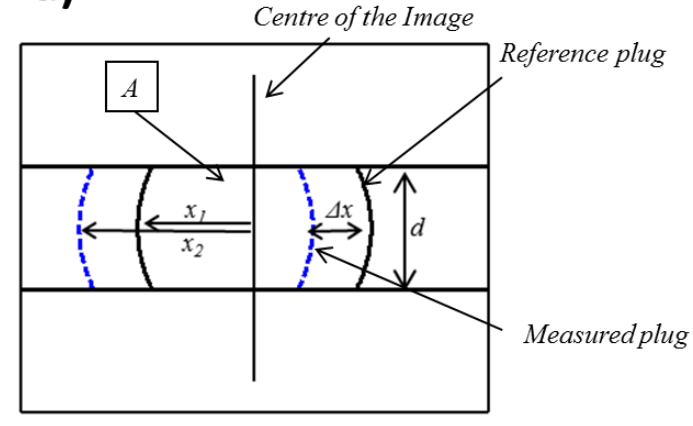

b)

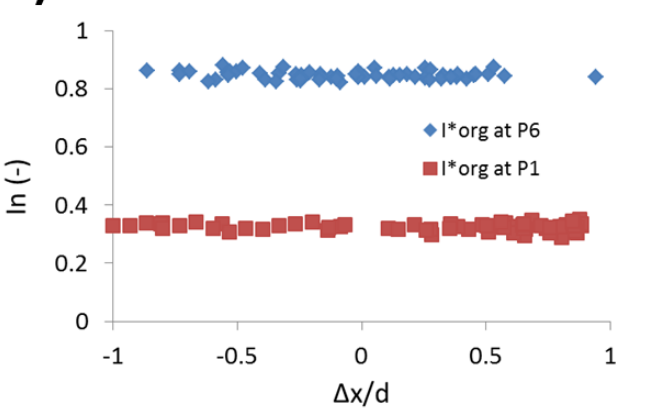

Fig. 3. (a) Schematic diagram of the plug area (A) and its position in the microchannel. The continuous (black) lines denote the reference plug and the dashed (blue) lines denote the plug under investigation. (b) Space-averaged light intensity in the organic phase, $\mathrm{I}_{\mathrm{org}}^{*}$, for plugs located at different positions in the microchannel for $\mathrm{Q}_{\text {tot }}=7.5$ $\mu \mathrm{L} / \mathrm{min}$.

A snapshot of the raw LIF image obtained for the organic phase for $\mathrm{Q}_{\text {tot }}=7.5 \mu \mathrm{L} / \mathrm{min}$ and phase ratio 1 with an initial concentration of europium(III) at $6 \mathrm{mg} / \mathrm{mL}$ is shown in Fig. 4a. The fluorescent signal of europium(III) in the organic phase is very strong because of the cation and ligand structures that have strong fluorescing properties [29]. Therefore, a low laser power of $3 \mathrm{~mW}$ was employed for the measurements in the organic phase. The recorded image was aligned with the reference plug and the intensity was then normalized according to Eq. (1) as shown in Fig. 4b. The phase-averaged intensity in the plug over 30 images is shown in Fig. 4c. Contrary to the organic phase, the $6 \mathrm{mg} / \mathrm{mL}$ europium(III) in the aqueous phase (nitric acid solution) has a very weak fluorescent 
signal. The use of the sensitive camera in combination with high laser power of $100 \mathrm{~mW}$, an important feature of the configuration, ensured that the emission signal from the europium(III) in the aqueous phase can be detected. Higher initial concentration of europium(III) in the aqueous phase would increase the signal intensity. However, this would also increase the concentration and intensity of europium(III) in the organic phase and lead to camera scale saturation. Fig. 4d shows a raw image of the europium(III) in the aqueous phase surrounded by a very intense fluorescent signal from the organic phase. Based on the intensity histogram of the raw image, a threshold value was used to binarize the image and reconstruct the interface as shown in Fig. 4e. Similar to Fig. 4c the intensity in the slug phase shown in Fig. 4f is phase-averaged over 30 images.

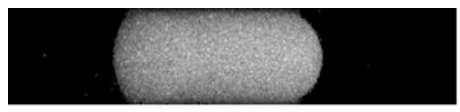

(a)

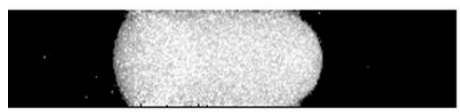

(b)

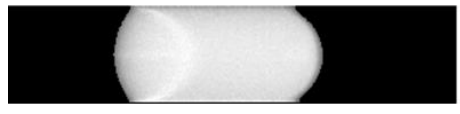

(c)

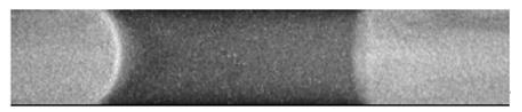

(d)

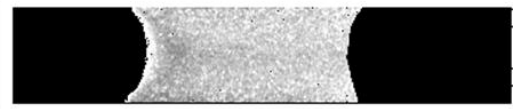

(e)

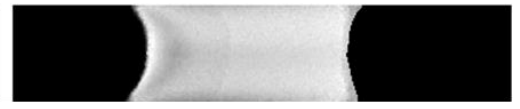

(f)

Fig. 4. Raw experimental images of (a) the plug and (d) slug; Normalised experimental images of (b) the plug and (e) slug; Phase-averaged of 30 normalized images of the (c) plug and (f) slug; $\mathrm{Q}_{\text {tot }}=7.5 \mu \mathrm{L} / \mathrm{min}$, initial concentration of europium(III) in aqueous phase is $6 \mathrm{mg} / \mathrm{mL}$.

\subsection{Analysis of the light propagation impact on the concentration profile in the aqueous phase}

It was found that the fluorescent light emitted from the organic phase is very strong and can affect the intensity of the light emitted from the aqueous phase. This is demonstrated in the example below. Initially, a solution of the aqueous phase, at equilibrium with the organic phase, was used. This solution was injected into the microchannel and its corresponding phase-averaged intensity, $\left\langle\mathrm{I}_{\mathrm{aq}, \mathrm{eq}}\right\rangle$, was obtained as shown in Fig. 5a. It can be seen that the intensity field is uniform, which is expected for an equilibrated solution. 


\section{a)}

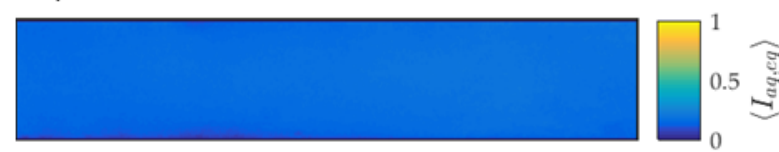

b)

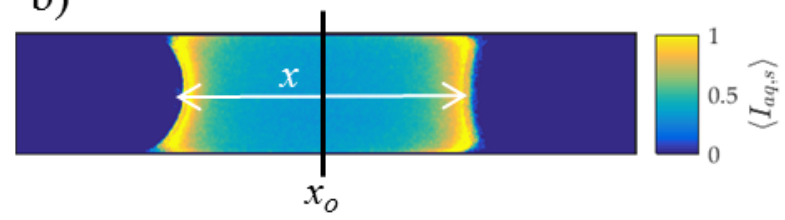

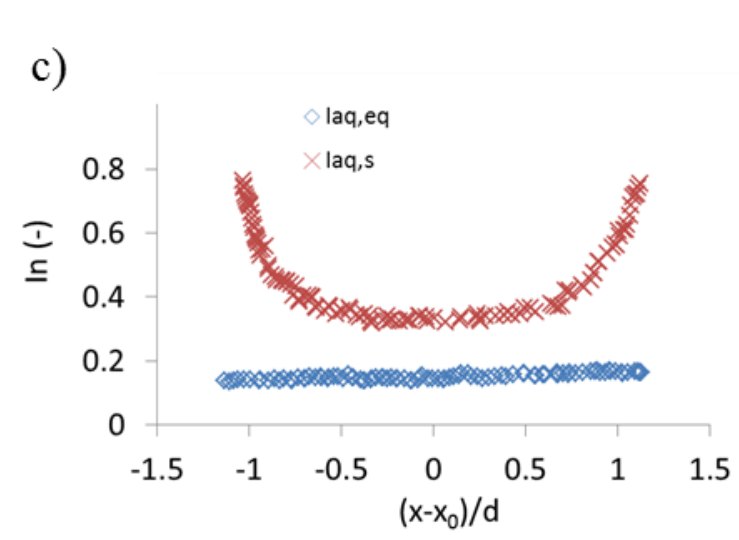

Fig. 5. Contour plot of the phase-averaged intensity in (a) equilibrated aqueous phase, $\left\langle\mathrm{I}_{\mathrm{aq}, \mathrm{eq}}\right\rangle$. (b) equilibrated aqueous phase $\left(0.6 \mathrm{mg} / \mathrm{ml}\right.$ of europium(III) concentration), $\left\langle\mathrm{I}_{\mathrm{aq}, \mathrm{s}}\right\rangle$ surrounded by equilibrated organic phase $(5.4 \mathrm{mg} / \mathrm{ml} \mathrm{of}$ europium(III) concentration). (c) Concentration profiles of $\left\langle\mathrm{I}_{\mathrm{aq}, \mathrm{eq}}\right\rangle$ and $\left\langle\mathrm{I}_{\mathrm{aq}, \mathrm{s}}\right\rangle$ along the centreline of the microchannel for $\mathrm{Q}_{\mathrm{tot}}=7.5 \mu \mathrm{L} / \mathrm{min}$; phase ratio 1 .

Subsequently, both phases at equilibrium were injected into the microchannel at $\mathrm{Q}_{\mathrm{tot}}=7.5 \mathrm{~mL} / \mathrm{min}$ and phase ratio equal to 1. Because the phases are at equilibrium, no mass transfer of europium(III) takes place. However, it can be seen from Fig $5 b$, that the intensity in the aqueous slug is not uniform anymore. There is a high intensity region close to the interface, which suggests that the emitted light in this region is affected by the organic phase fluorescence. It should be noted that $\mathrm{x}$ and $\mathrm{x}_{\mathrm{o}}$ in Fig $5 \mathrm{~b}$ refer to the size of the slug and the position of the centre of the image, respectively. To quantify this behaviour, intensity profiles of $\left\langle\mathrm{I}_{\mathrm{aq}, \mathrm{eq}}\right\rangle$ and $\left\langle\mathrm{I}_{\mathrm{aq}, \mathrm{s}}\right\rangle$ along the centerline of the microchannel are shown in Fig. $5 \mathrm{c}$, where $\mathrm{x}_{\mathrm{o}}$ is the centre of the channel. The profile of $\left\langle\mathrm{I}_{\mathrm{aq}, \mathrm{eq}}\right\rangle$ remains constant, while the profile for $\left\langle\mathrm{I}_{\mathrm{aq}, \mathrm{s}}\right\rangle$ is almost constant in the region $\left|\left(\mathrm{x}-\mathrm{x}_{\mathrm{o}}\right) / \mathrm{d}\right|<0.75$, but increases close to the interfaces at the front and the back of the slug. Compared to $\left\langle\mathrm{I}_{\mathrm{aq}, \mathrm{eq}}\right\rangle$ the intensity is almost two times higher near the centre of the slug and 2-6 times higher near the interfaces. Similar trends were observed for the other flow rates tested, i.e. $\mathrm{Q}_{\mathrm{tot}}=5 \mathrm{and} 10 \mathrm{~mL} / \mathrm{min}$. It was found that the fluorescent light emitted from the organic phase is very strong and can affect the intensity of the registered light emitted from the aqueous phase. A suitable aqueous phase background needs to be established that takes into account this effect. To this end, experiments were carried out in plug flow with the organic phase with europium(III) and the aqueous phase without any europium(III). To avoid any mass transfer between the phases, a high concentration of $3 \mathrm{M}$ nitric acid was used in the aqueous phase [30, 31]. Two cases with low (1 mg/mL) and equilibrated (high) $(5.4$ $\mathrm{mg} / \mathrm{mL}$ ) europium(III) concentration in the organic phase were investigated. Fig. 6a shows the phase-averaged intensity measurements of $\left\langle\mathrm{I}_{\mathrm{aq}, \mathrm{s} 1}\right\rangle$ for organic phase with high europium(III) concentration. Again, there is high light intensity 
near the edges of the slug. However, for the low concentration of europium(III) in the organic phase, the averaged intensity profile in the aqueous slug $\left\langle\mathrm{I}_{\mathrm{aq}, \mathrm{s} 2}\right\rangle$ shows that the increase in light intensity near the interfaces is not as large while it occupies a limited region as shown in Fig. 6b. Intensity profile lines along the centreline for both concentrations in the organic phase are shown in Fig. 6c, for two different positions in the microchannel, namely, P1 and P6. Interestingly, there is little difference between the intensity profiles for low and high concentration at P1 and P6, indicating that there is indeed negligible extraction of europium(III) from the organic to the aqueous phase along the channel. This analysis indicates that the fluorescence signal of the aqueous phase is due to the background reflection of the organic phase rather than the presence of europium(III) in the slug. The low fluorescence of europium(III) in the aqueous phase is due to the low molar absorptivity and poor quantum yield of europium(III) [32].

a)

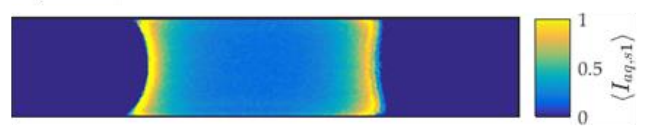

b)

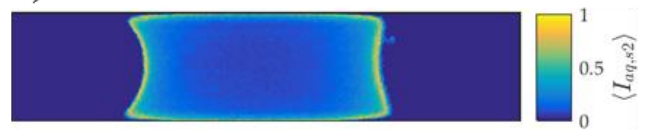

c)

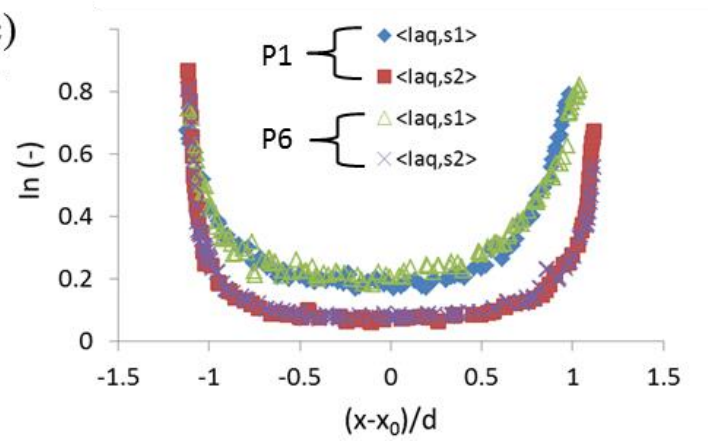

Fig. 6. Contour plot of the phase-averaged intensity in the $3 \mathrm{M}$ nitric acid solution for: $(\mathbf{a})\left\langle\mathrm{I}_{\mathrm{aq}, \mathrm{s} 1}\right\rangle$, with high (equilibrated) concentration $(5.4 \mathrm{mg} / \mathrm{mL})$ of europium(III) in the organic phase; (b) $\left\langle\mathrm{I}_{\mathrm{aq}, \mathrm{s} 2}\right\rangle$, with low concentration $(1 \mathrm{mg} / \mathrm{mL})$ of europium(III) in the organic phase; (c) Concentration profiles of $\left\langle\mathrm{I}_{\mathrm{aqs} 1}\right\rangle$ and $\left\langle\mathrm{I}_{\mathrm{aq}, \mathrm{s} 2}\right\rangle$ along the centerline of the microchannel at two different positions, $\mathrm{P} 1$ and $\mathrm{P} 6$ for $\mathrm{Q}_{\text {tot }}=7.5 \mu \mathrm{L} / \mathrm{min}$; phase ratio 1 .

To improve the accuracy of the intensity measurements of $\left\langle\mathrm{I}_{\mathrm{aq}, \mathrm{s}}\right\rangle$ it is necessary to remove the influence of the surrounding organic phase. For the results shown in Fig. $5 \mathrm{~b},\left\langle\mathrm{I}_{\mathrm{aq}, \mathrm{s} 1}\right\rangle$ was subtracted from $\left\langle\mathrm{I}_{\mathrm{aq}, \mathrm{s}}\right\rangle$, because in both cases the same concentration of europium(III) was present in the organic phase. Fig. 7 shows the intensity profiles along the channel centreline for $\left\langle\mathrm{I}_{\mathrm{aq}, \mathrm{eq}}\right\rangle,\left\langle\mathrm{I}_{\mathrm{aq}, \mathrm{s}}\right\rangle,\left\langle\mathrm{I}_{\mathrm{aq}, \mathrm{s} 1}\right\rangle$ and the difference between $\left\langle\mathrm{I}_{\mathrm{aq}, \mathrm{s}}\right\rangle$ and $\left\langle\mathrm{I}_{\mathrm{aq}, \mathrm{s} 1}\right\rangle$. In the regions $\left|\left(x-x_{0}\right) / d\right|>0.75$, the profile of $\left\langle\mathrm{I}_{\mathrm{aq}, \mathrm{s}}\right\rangle-\left\langle\mathrm{I}_{\mathrm{aq}, \mathrm{s} 1}\right\rangle$, deviates from the true profile of $\left\langle\mathrm{I}_{\mathrm{aq}, \mathrm{eq}}\right\rangle$ with errors larger than $20 \%$, while in the region $\left|\left(x-x_{0}\right) / d\right|<0.75$ close to the centerline of the plug, a good agreement is observed with errors less than 3\%. For the analysis of the aqueous phase, in the following section, the effect of the surrounding light from the organic phase was taken into consideration according to the following two main steps: 
1) The space-averaged intensity of the organic phase, $\left\langle\mathrm{I}_{\mathrm{org}}\right\rangle^{*}$ is estimated to obtain the average amount of europium(III) concentration that is present in the plug for each $\mathrm{Q}_{\text {tot }}$.

2) Based on the concentration of europium(III) in the organic phase for each of the three different flow rates investigated, a pixel by pixel interpolation is carried out between $\left\langle\mathrm{I}_{\mathrm{aq}, \mathrm{s} 1}\right\rangle$, and $\left\langle\mathrm{I}_{\mathrm{aq}, \mathrm{s} 2}\right\rangle$ to generate three different background images in the slug for each total flow rate. These images are then subtracted from the normalised images obtained for the slug. It should be noted that the high intensity areas near the edges of the slug, up to $5 \%$ of the plug size, were also removed and did not influence the interpretation of the experimental data.

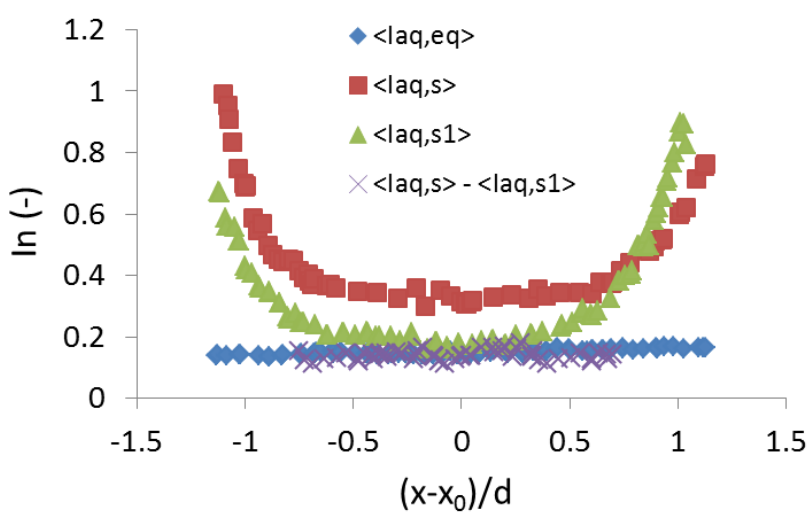

Fig. 7. Concentration profiles of $\left\langle\mathrm{I}_{\mathrm{aq}, \mathrm{eq}}\right\rangle,\left\langle\mathrm{I}_{\mathrm{aq}, \mathrm{s}}\right\rangle,\left\langle\mathrm{I}_{\mathrm{aq}, \mathrm{s} 1}\right\rangle$ and the difference between $\left\langle\mathrm{I}_{\mathrm{aq}, \mathrm{s}}\right\rangle$ and $\left\langle\mathrm{I}_{\mathrm{aq}, \mathrm{s} 1}\right\rangle$ along the centerline of the microchannel for $\mathrm{Q}_{\text {tot }}=7.5 \mu \mathrm{L} / \mathrm{min}$; phase ratio 1 .

\section{Mass transfer of europium(III) in the microchannel}

For the characterisation of the mass transfer performance in microchannels, two parameters are mainly used, i.e. the extraction efficiency $\left(\% \mathrm{E}_{\mathrm{eff}}\right)$ and the overall volumetric mass transfer coefficient $\left(\mathrm{k}_{\mathrm{L}} \alpha\right)$.

\subsection{Extraction efficiency $\left(\% \mathrm{E}_{\text {eff }}\right)$}

As extraction efficiency is defined the ratio of the amount of europium(III) transferred from the aqueous to the organic phase, to the maximum amount transferrable:

$\% \mathrm{E}_{\mathrm{eff}}=\frac{\mathrm{C}_{\mathrm{aq}, \mathrm{fin}}-\mathrm{C}_{\mathrm{aq}, \mathrm{t} 0}}{\mathrm{C}_{\mathrm{aq}, \mathrm{eq}}-\mathrm{C}_{\mathrm{aq}, \mathrm{to}}}$

where $\mathrm{C}_{\mathrm{aq}, \mathrm{t} 0}$ is the initial concentration of europium(III) in the aqueous phase, $\mathrm{C}_{\mathrm{aq}, \mathrm{fin}}$ is the concentration of europium(III) in the aqueous phase at each position (P1-P7), and $\mathrm{C}_{\mathrm{aq}, \mathrm{eq}}$ is the concentration of the europium(III) 
in the aqueous phase at equilibrium with the organic phase at infinite time $(t=\infty)$. $C_{a q, e q}$ was found from the equilibrium experiments.

The mass transfer of europium(III) during plug formation at the T-junction inlet is demonstrated in Fig. 8 for different total flow rates and flow rate ratio equal to 1 . The aqueous continuous phase $(6 \mathrm{mg} / \mathrm{mL}$ of europium(III) in nitric acid) was introduced at the same axis as the main channel, while the organic phase (D80/TBP/CMPO) was introduced perpendicular to the main channel. Once the two fluids come into contact at the T-junction, europium(III) is transferred from the aqueous phase to the organic plug. The plug formation time increases as the total flow rate decreases. As a result, the two phases will be in contact for longer time during plug formation and more europium(III) will be transferred at low flow rates compared to the high ones ("same position" column). It can be seen, that the highest concentration of europium(III) is close to the interface, whilst the concentration profiles follow the circulation pattern expected during plug formation [22].
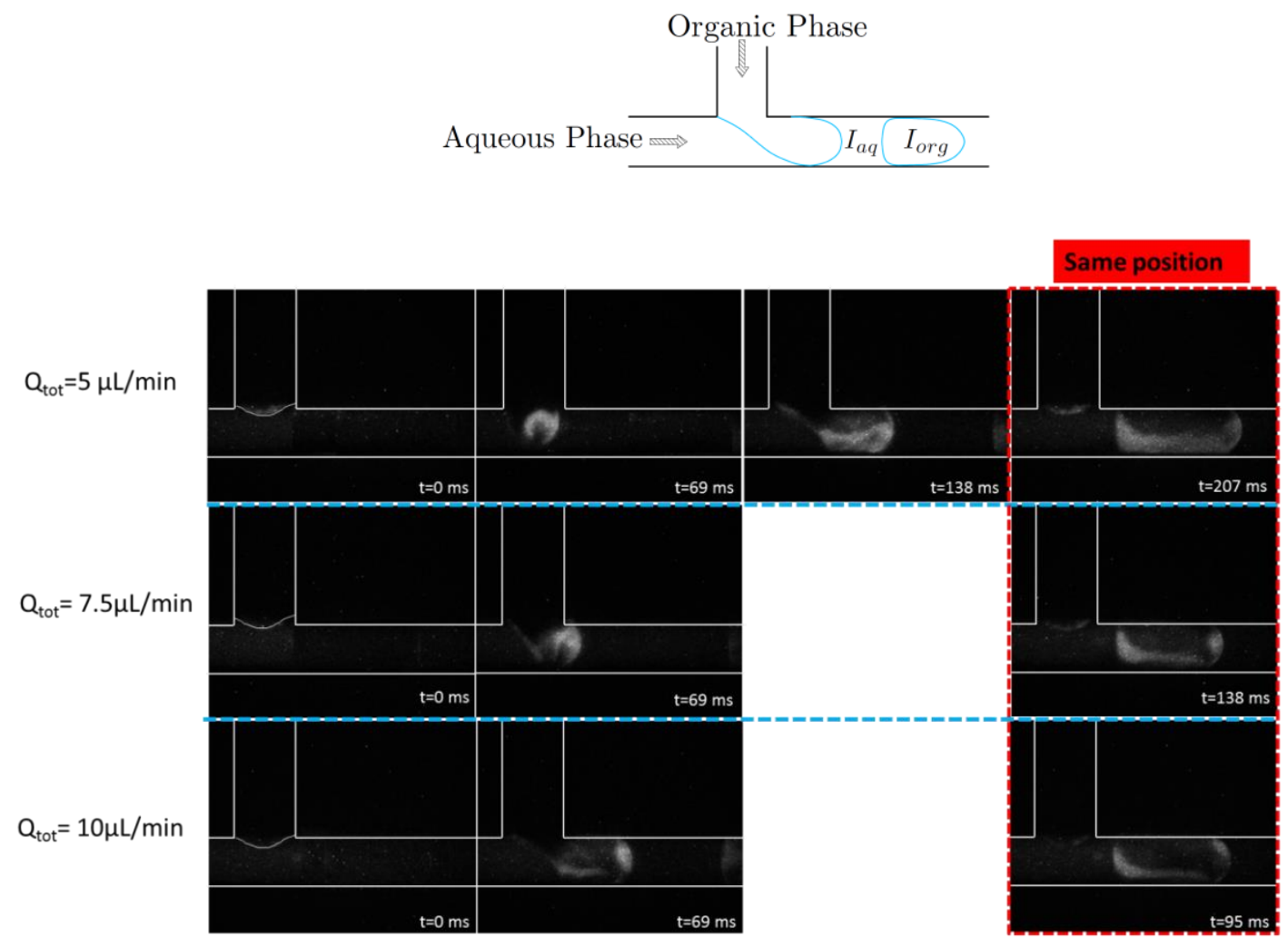

Fig. 8. Evolution of plug and europium(III) concentration fields in the mixing zone at flow rate ratio equal to 1.

The normalised phase-averaged slug $\left\langle\mathrm{I}_{\mathrm{aq}}\right\rangle$ and plug $\left\langle\mathrm{I}_{\mathrm{org}}\right\rangle$ intensity fields at $1 \mathrm{~mm}$ downstream (P1) of the mixing zone are shown in Fig. 9 for three different $\mathrm{Q}_{\text {tot. }}$ The intensity (or concentration) fields, in both the aqueous and organic phases, display several distinctive features. The intensity fields for $\mathrm{Q}_{\mathrm{tot}}=5 \mu \mathrm{L} / \mathrm{min}$ in the aqueous slug and in the organic plug are 
lower and higher, respectively, when compared to the other two flow rates. The concentration fields in the main channel seem to follow the internal circulation patterns expected in both the slugs and plugs [33]. This is more evident from the concentration field of $\left\langle\mathrm{I}_{\mathrm{org}}\right\rangle$ at $\mathrm{Q}_{\text {tot }}=10 \mu \mathrm{L} / \mathrm{min}$. This behaviour was also observed by Bai et al. (2016) [27] who investigated the mass transfer of Rhodamine $6 \mathrm{G}$ from water into an ionic liquid and found that the circulation patterns were more obvious when the total flow rate increased. A larger concentration of europium(III) in the plug is observed near the

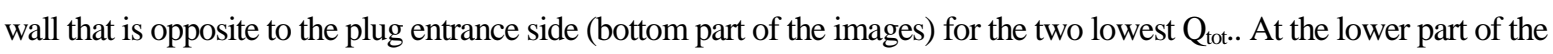
channel there is an interface which increases the mass transfer between the phases. There is a different distribution of the concentration of europium(III) in the organic phase for the highest $Q_{\text {tot. }}$ At low $Q_{\text {tot }}$ the circulation in the plugs is weak [15] and slows the distribution of the europium(III) in the plug. At the highest $\mathrm{Q}_{\mathrm{tot}}=10 \mu \mathrm{L} / \mathrm{min}$ a better distribution of the europium(III) is observed in the plug because of increased recirculation intensity; in addition at the highest flowrate there is less amount of Eu(III) transferred in the plug up to the measurement location P1, which is distributed faster.

For all $\mathrm{Q}_{\text {tot }}$ investigated, the europium(III) tended to accumulate in the front end of the slug and the back end of the plug. A similar behaviour was also observed by Bai et al. [27] who reported that the vortical structures were more obvious near the front of the slug rather than the rear [34] and promoted mass transfer at the slug front. Good agreement was found between the amount of europium(III) leaving the aqueous slug and transferring into the organic plug. Since the mass balance was confirmed with average error less than 3\%, for the rest of the cases studied the concentration of europium(III) was calculated only in the organic phase, where the maximum error associated to the organic phase is less than $2 \%$.

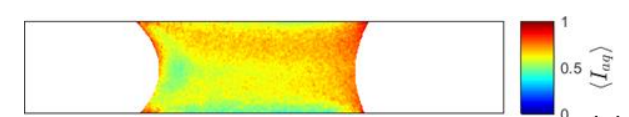

(a)

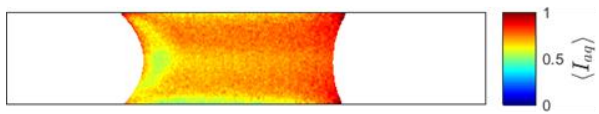

(b)

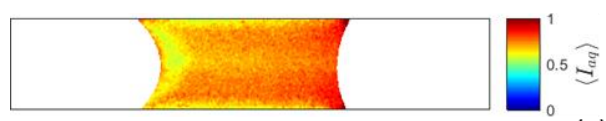

(c)
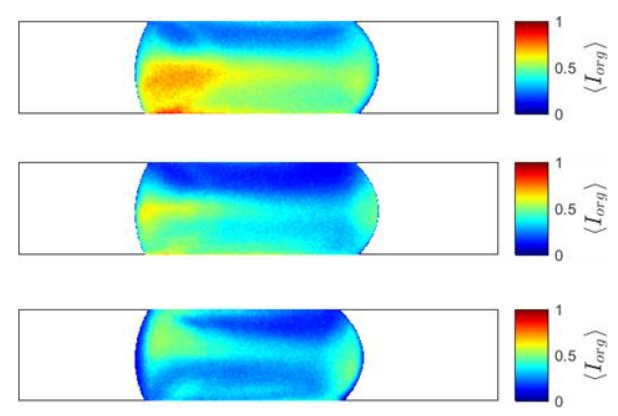

Fig. 9. Contour plots of the phase-averaged aqueous phase (slug) intensity, $\left\langle\mathrm{I}_{\mathrm{aq}}\right\rangle$ and organic phase (plug) intensity, $\left\langle\mathrm{I}_{\text {org }}\right\rangle$ at $\mathrm{P} 1$ for: (a) $\mathrm{Q}_{\text {tot }}=5 \mu \mathrm{L} / \mathrm{min}$; (b) $\mathrm{Q}_{\text {tot }}=7.5 \mu \mathrm{L} / \mathrm{min}$; (c) $\mathrm{Q}_{\text {tot }}=10 \mu \mathrm{L} / \mathrm{min}$. (Flow rate ratio $=1$ ) 
The percentage of europium(III) extracted $(\% \mathrm{E})$ at position P1 for different phase ratios is shown in Fig. 10a. As can be seen, significant mass transfer of about 20-40\% (depending on the total flow rate) has already occurred at this early position in the channel, which agrees with the numerical simulations by Riaud et al. [25] that up to $40 \%$ of the mass transfer happens at the beginning of the channel. The extraction percentage $(\% \mathrm{E})$ was found to decrease with increasing total flow rate for all phase ratios. This is attributed to the decrease in contact time with increasing flow rate, since, as can be seen from Fig. 11 the specific interfacial area $(\alpha)$ does not change with flow rate for a fixed flow rate ratio. The specific interfacial area available for mass transfer can be calculated by assuming that the plug has a cylindrical body and two hemispherical caps at the front and back ends. For a fixed total flow rate, the $\% \mathrm{E}$ decreased with decreasing the organic to aqueous phase flow rate ratio. This is linked to the decrease in interfacial area as can be seen in Figure 11 . The extraction efficiency $\left(\% \mathrm{E}_{\mathrm{eff}}\right)$ at $\mathrm{P} 1$ is shown in Fig. 10b. The efficiency decreases with an increase in total flow rate similar to $\%$ E. However, in contrast to $\% \mathrm{E}$, better extraction efficiency is achieved by decreasing the phase ratio at constant total flow rate.

a)

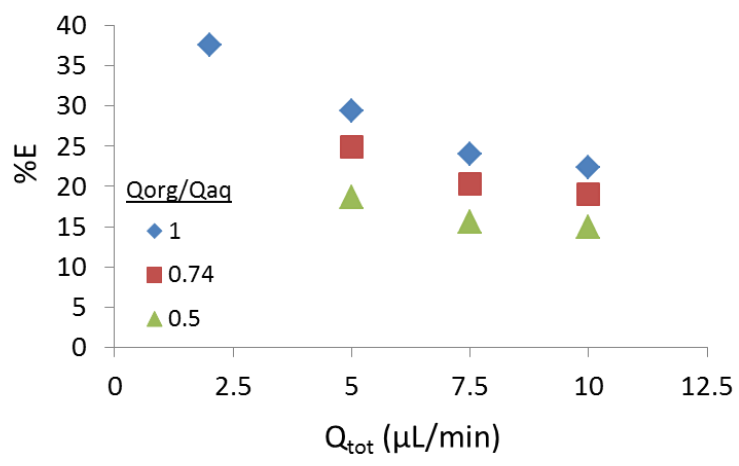

b)

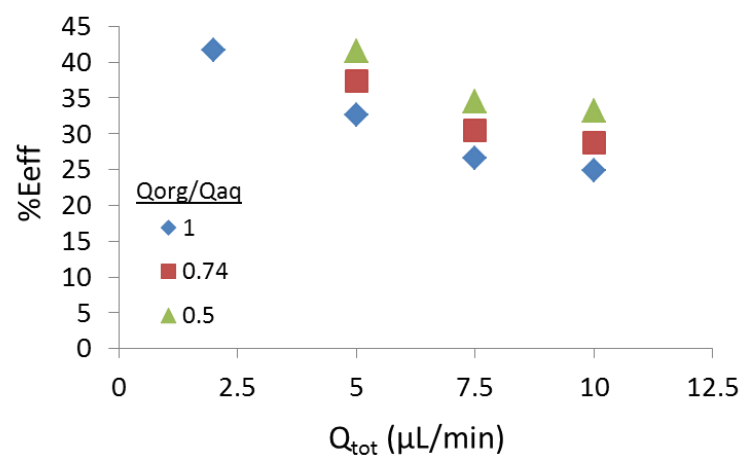

Fig. 10. (a) Percentage of europium(III) extracted in the organic phase $(\% \mathrm{E})$ and $(\mathbf{b})$ extraction efficiency $\left(\% \mathrm{E}_{\text {eff }}\right)$ at $1 \mathrm{~mm}$ from the mixing zone (P1).

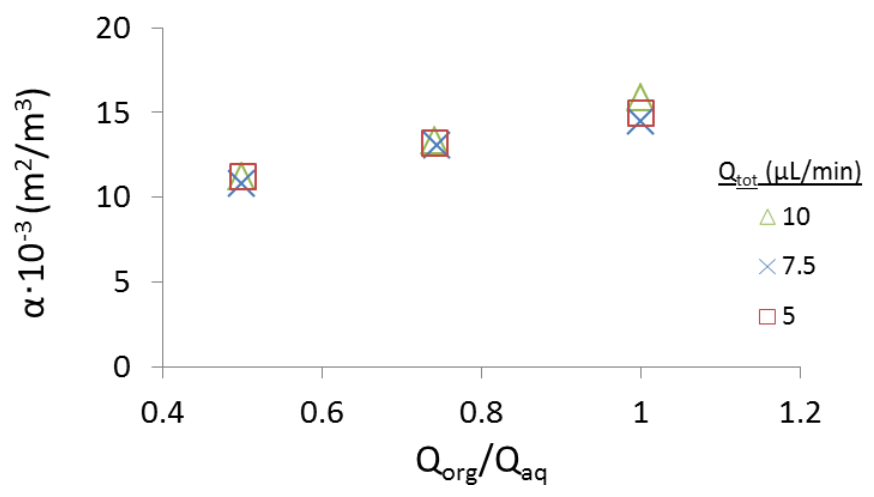

Fig. 11. Specific plug interfacial area $(\alpha)$ at different flow rates and phase ratios. 
To investigate further the effect of the phase ratio for the same residence times on the extraction performance of the system, the feed of the aqueous solution was kept constant at $5 \mu \mathrm{L} / \mathrm{min}$, whilst the feed of the organic phase was decreased. In Fig. 12 the $\% \mathrm{E}$ and the $\% \mathrm{E}_{\text {eff }}$ are plotted against the residence time. The residence time was calculated by using the velocity of the plug $\left(\mathrm{u}_{\mathrm{p}}\right)$, which was measured from successive camera images, as $\tau=\mathrm{L}_{\mathrm{ch}} / \mathrm{u}_{\mathrm{p}}$.

As can be seen the $\%$ E increases significantly at short residence times and then increases more slowly. The mass transfer is very high at the inlet where the phases first join because the initial concentration differences between the two phases are large and the mixing at the inlet is intense. Once the plug flow develops, circulation in the plugs and slugs will help mass transfer. However, once the circulation patterns develop, the mixing depends mainly on the diffusion across the concentration gradients (such as those shown in Fig. 9) rather than the velocity of circulation. At later residence times, therefore, further downstream the channel the increase in $\% \mathrm{E}$ is more slow. As can be seen, the $\% \mathrm{E}$ is higher when the phase ratio is increased. However, the $\% \mathrm{E}_{\text {eff }}$ (Fig. 12b) is similar for both cases, even though the interfacial area is larger at phase ratio 1 (as shown in Fig. 11).
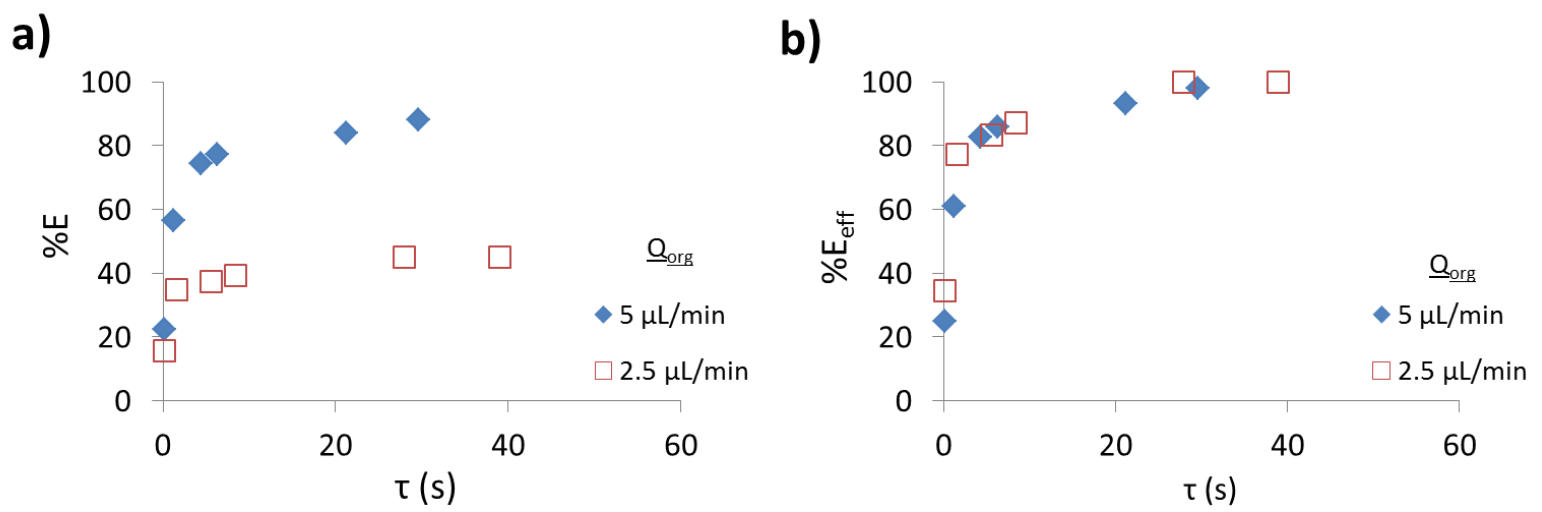

Fig. 12. (a) Percentage of europium(III) extracted in the organic phase $(\% \mathrm{E})$ and (b) extraction efficiency $\%\left(\mathrm{E}_{\mathrm{eff}}\right)$ as a function of residence time at constant aqueous phase flow rate equal to $5 \mu \mathrm{L} / \mathrm{min}$ and flow rate ratios of 1 and 0.5 .

In Fig. 13 the $\% \mathrm{E}_{\text {eff }}$ is plotted as a function of the residence time for different total flow rates at phase ratio 1 . As can be seen, at residence times less than $10 \mathrm{~s}$, the $\% \mathrm{E}_{\text {eff }}$ follows the same trend for all $\mathrm{Q}_{\text {tot }}$ (inset in Fig. 13). At longer residence times, $\% \mathrm{E}_{\text {eff }}$ was slightly increased for increased $\mathrm{Q}_{\text {tot. }}$ This change in behaviour suggests that in the beginning of the channel mass transfer is mainly affected by the residence time. After a certain time the intensity of the circulations inside the two phases which increases with total flow rate [2] also contributes, even though slightly to mass transfer. For all cases the extraction efficiency reached about $80 \%$ in the first $6 \mathrm{~s}$. 


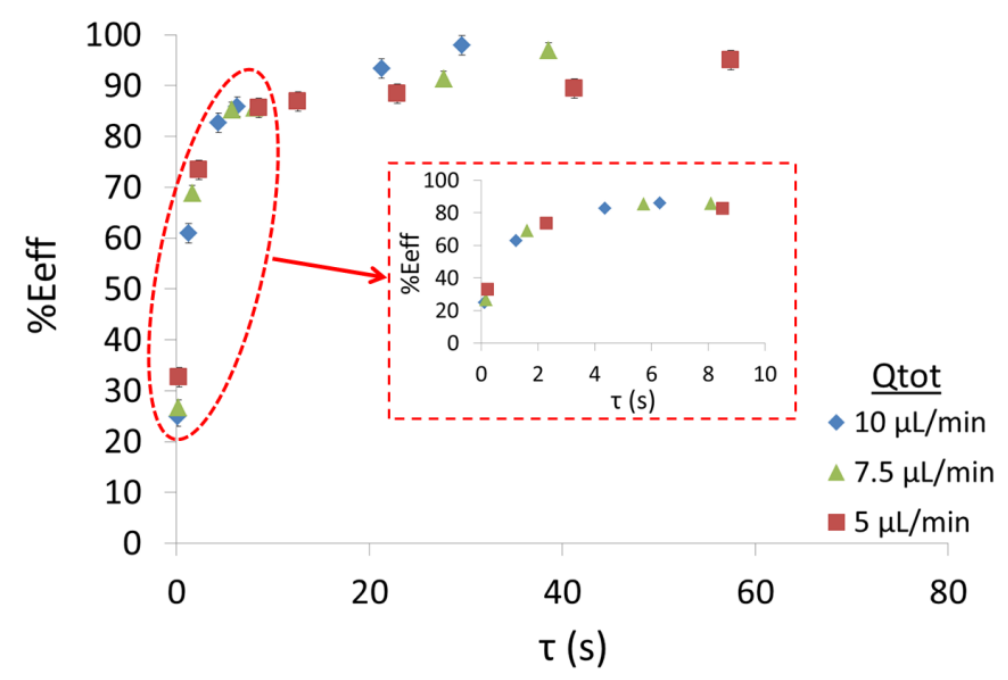

Fig. 13. Extraction efficiency as a function of residence time for different total flow rates at phase flow rate ratio equal to 1 .

The following equation can be fitted to the experimental data on extraction percentage:

$\% \mathrm{E}=0.47 \frac{\mathrm{u}_{\mathrm{mix}}}{\mathrm{L}_{\mathrm{ch}}}+7.65 \cdot \mathrm{K} \cdot \mathrm{r}$

where $\mathrm{K}$ is the distribution coefficient and $\mathrm{r}$ is the organic to aqueous phase flow rate ratio. The above correlation can describe the experimental data (Fig. 14) with an average deviation of $8 \%$ for residence times higher than $1 \mathrm{~s}$, and extraction efficiency lower than $90 \%$.

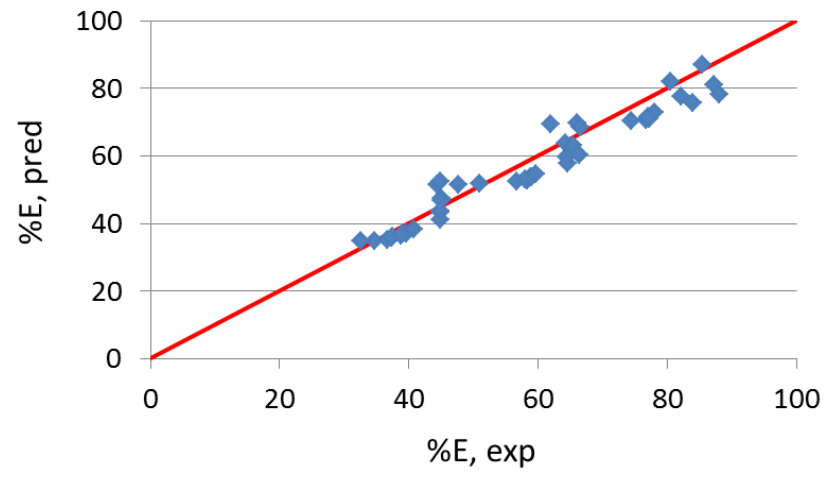

Fig. 14. Comparison of experimental and predicted percentage extraction (\%E).

\subsection{Mass transfer coefficient}

The rate of mass transfer of europium(III) from the aqueous to the organic phase is given by: 
$\frac{\mathrm{dC}_{\mathrm{aq}}}{\mathrm{dt}}=-\mathrm{k}_{\mathrm{L}} \alpha\left(\mathrm{C}_{\mathrm{aq}}-\mathrm{C}_{\mathrm{aq}, \mathrm{eq}}\right)$

where, $\mathrm{C}_{\mathrm{aq}}$ is the concentration of the europium(III) in the aqueous phase (at time $\mathrm{t}$ ).

Based on the average concentrations measured, the overall mass transfer coefficients for the europium(III) extraction were evaluated, to enable direct comparison of the mass transfer performance of the microchannel with other contactors (Table 3). Integrating Eq. 5 over the whole channel length from the initial contact time of the two phases in the $\mathrm{T}$-junction $(\mathrm{t}=0)$ to $\mathrm{t}=\tau$, the residence time in the reactor, the mass transfer coefficient can be found from Eq. 5 as follows [35]:

$\mathrm{k}_{\mathrm{L}} \alpha=\frac{1}{\mathrm{t}_{\mathrm{i}}} \ln \left(\frac{\mathrm{C}_{\mathrm{aq}, \mathrm{eq}}-\mathrm{C}_{\mathrm{aq}, \mathrm{to}}}{\mathrm{C}_{\mathrm{aq}, \mathrm{eq}}-\mathrm{C}_{\mathrm{aq}, \mathrm{fin}}}\right)$

In general, $\mathrm{k}_{\mathrm{L}} \alpha$ ranged from 0.05 to $3.3 \mathrm{~s}^{-1}$, and was one to two orders of magnitude higher than in conventional contactors such as mixer settlers and pulsed columns and of similar order with centrifugal contactors (Table 3). In Figs $15 \mathrm{a}$ and $\mathrm{b}$ the overall mass transfer coefficients are shown at different locations along the channel and different residence times respectively. $\mathrm{C}_{\mathrm{aq}, \mathrm{t} 0}$ was the initial concentration of europium in the aqueous phase, whilst $\mathrm{C}_{\mathrm{aq}, \mathrm{fin}}$ was the concentration of the aqueous phase at each of the different positions (P1 to P7 i.e.1 to $241 \mathrm{~mm}$ ). The overall mass transfer coefficients shown in these graphs were averaged from the beginning of the channel where the fluids join, to each of the different positions (P1-P7).

Table 3. Overall mass transfer coefficient in different two-phase contactors.

\begin{tabular}{|c|c|c|c|}
\hline Contactor & Two-phase system & $\mathbf{k}_{\mathbf{L}} \boldsymbol{\alpha} / \mathbf{s}^{-1}$ & Reference \\
\hline $\begin{array}{l}\text { Quartz microchannel } \\
\qquad(\mathrm{ID}=\mathbf{2 0 0} \boldsymbol{\mu \mathrm { m }})\end{array}$ & $\mathrm{TBP} /$ kerosene-U-HNO${ }_{3}$ & $0.05-3.3$ & $\begin{array}{l}\text { Present } \\
\text { work }\end{array}$ \\
\hline $\begin{array}{c}\text { Y-junction PTFE } \\
\text { microchannels } \quad(\text { ID }=0.5 \\
\mathrm{mm})\end{array}$ & Kerosene/acetic acid/water & $0.05-0.4$ & {$[36]$} \\
\hline Annular pulsed column & $\mathrm{TBP} /$ kerosene-U-HNO${ }_{3}$ & $0.009-0.012$ & {$[37]$} \\
\hline $\begin{array}{c}\text { T-junction serpentine } \\
\text { microchannels } \\
(\mathrm{ID}=0.278 \text { and } 0.319 \mathrm{~mm})\end{array}$ & $\mathrm{H}_{2} \mathrm{O}$-acetone-toluene & $0.001-0.19$ & {$[38]$} \\
\hline
\end{tabular}




\begin{tabular}{|cccc|}
\hline Mixer-settler & $\mathrm{NPH}-\mathrm{TBP}-\mathrm{HNO}_{3}$ & $0.5-13.3\left(\mathrm{x} 10^{-5}\right)$ & {$[39]$} \\
\hline Centrifugal extractor & aqueous $\mathrm{NaOH}-($ butyl acetate, iso-amyl & $0.2-2$ & {$[40]$} \\
& acetate, hexyl acetate) & & \\
\hline
\end{tabular}

Initially, the mass transfer coefficients decreased with increasing channel length or residence time, while after about $100 \mathrm{~mm}$ or $20 \mathrm{~s}$ they remained almost constant. As discussed above significant mass transfer happens at the inlet. The mass transfer coefficients include both the mass transfer at the inlet as well as in the main channel up to the point of measurement. As a result, at short lengths (or residence times) the effect of inlet is large; this is the reason that $\mathrm{k}_{\mathrm{L}} \alpha$ reduces with channel length or residence time. For a longer channel length (about $100 \mathrm{~mm}$ or 20 ), the effect of the inlet on the overall mass transfer coefficient is reduced and the $\mathrm{k}_{\mathrm{L}} \alpha$ values remain almost constant after that. For a certain channel length, $\mathrm{k}_{\mathrm{L}} \alpha$ slightly increased when the total flow rate increased. When plotted against the residence time, however, the mass transfer coefficient was almost the same for all the cases studied (Fig 15b).
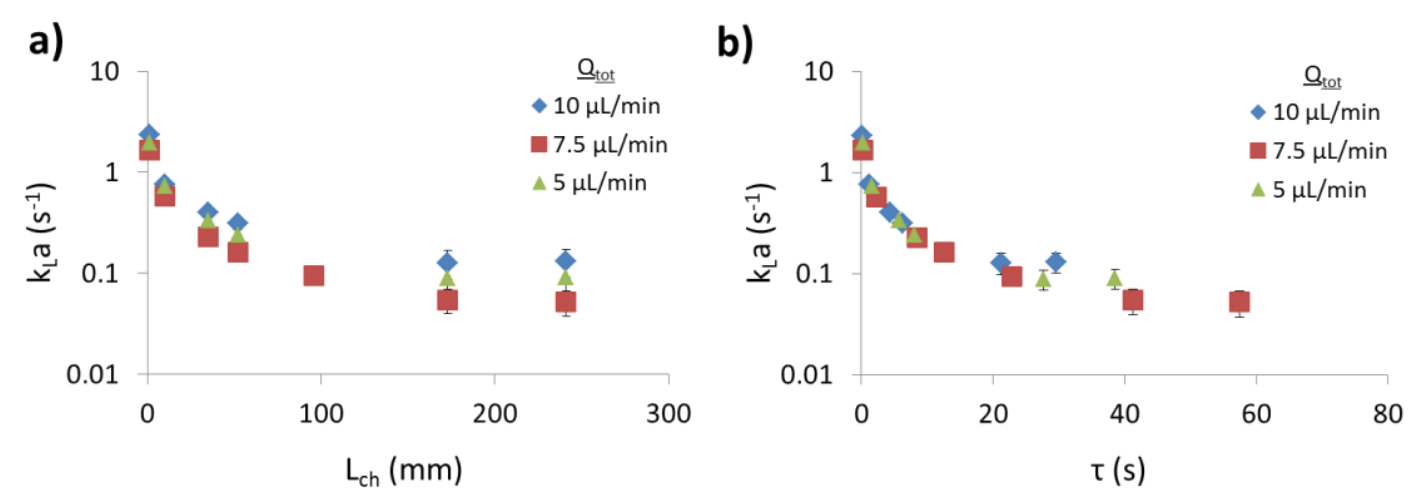

Fig. 15. Overall mass transfer coefficient (a) at different positions along the channel and (b) as a function of residence time, for phase flow rate ratio equal to 1 .

\section{Conclusions}

In this paper the extraction of europium(III) from an aqueous to an organic phase in a microchannel was experimentally investigated using a novel micro Laser Induced Fluorescence (micro-LIF) technique. The technique was able to measure the transfer of europium from the one phase to the other at different positions along 
the channel. The aqueous phase was a nitric acid solution $(1 \mathrm{M})$ while the organic phase was a mixture of $\mathrm{TBP}(1.2 \mathrm{M}) / \mathrm{CMPO}(0.2 \mathrm{M})$ in Exxsol D80. A methodology was developed to calculate the europium(III) concentration profiles in each phase from the intensity of the emitted light. The method was able to take into account the variation of the plug and slug positions in the images and the effect that the high light intensity of the organic phase has on the aqueous phase. From the concentration profiles the amount of europium transferred from one phase to the other was estimated and was found to balance with an average error of less than $3 \%$. The results showed that there was significant mass transfer in the mixing zone close to the channel inlet with extractions between 20 and $40 \%$ depending on the total flow rate. The specific interfacial area was calculated from the geometric characteristics of the plug and varied from 10000 to $15000 \mathrm{~m}^{2} / \mathrm{m}^{3}$. High extraction efficiency $(\sim 80 \%)$ was achieved at short residence times (within 6 s), whilst the overall volumetric mass transfer coefficients varied between 0.05 and $3.3 \mathrm{~s}^{-1}$.

\section{Nomenclature}

\begin{tabular}{|c|c|}
\hline $\mathrm{C}_{\mathrm{aq}, \mathrm{t} 0}$ & Concentration of europium(III) in aqueous phase at $t_{0}\left[\mathrm{~mol} \mathrm{~L}^{-1}\right]$ \\
\hline $\mathrm{C}_{\mathrm{aq}, \text { fin }}$ & Final concentration of europium(III) in aqueous phase $\left[\mathrm{mol} \mathrm{L}^{-1}\right]$ \\
\hline $\mathrm{C}_{\mathrm{aq}, \mathrm{eq}}$ & Concentration of europium(III) in aqueous phase at equilibrium $\left[\mathrm{mol} \mathrm{L}^{-1}\right]$ \\
\hline $\mathrm{C}_{\mathrm{aq}}$ & Concentration of europium(III) in aqueous phase $\left[\mathrm{mol} \mathrm{L}^{-1}\right]$ \\
\hline $\mathrm{d}$ & Channel diameter $[\mathrm{mm}]$ \\
\hline $\mathrm{E}$ & Extraction percentage $[\%]$ \\
\hline I & Intensity $[-]$ \\
\hline $\mathrm{k}_{\mathrm{L}}$ & Overall mass-transfer coefficient $[\mathrm{m} / \mathrm{s}]$ \\
\hline $\mathrm{k}_{\mathrm{L}} \alpha$ & Overall volumetric mass transfer coefficient $\left[\mathrm{s}^{-1}\right]$ \\
\hline $\mathrm{K}$ & Distribution ratio \\
\hline $\mathrm{L}$ & Length $[\mathrm{m}]$ \\
\hline Q & Volumetric flow rate of fluid $\left[\mathrm{m}^{3} / \mathrm{s}\right]$ \\
\hline
\end{tabular}


organic-to-aqueous phase ratio

\section{Greek symbols}

$\begin{array}{ll}\alpha & \text { Specific interfacial area }\left[\mathrm{m}^{2} \mathrm{~m}^{-3}\right] \\ \mu & \text { Dynamic viscosity }\left[\mathrm{kg} \mathrm{m}^{-1} \mathrm{~s}^{-1}\right] \\ \mathrm{p} & \text { Density }\left[\mathrm{kg} \mathrm{m}^{-3}\right] \\ \tau & \text { Residence time }[\mathrm{s}], \tau=\mathrm{L}_{\mathrm{ch}} / \mathrm{u}_{\mathrm{p}}\end{array}$

\section{Subscripts}

$\begin{array}{ll}\text { aq } & \text { aqueous } \\ \text { ch } & \text { channel } \\ \text { eq } & \text { equilibrium } \\ \text { mix } & \text { mixture } \\ \text { org } & \text { organic } \\ \mathrm{p} & \text { plug } \\ \mathrm{r} & \text { reactor } \\ \text { ref } & \text { reference }\end{array}$




\section{Acknowledgements}

The work was supported by an EPSRC grant on Feasibility Studies in Energy (EP/P034101/1) and the EPSRC Programme grant MEMPHIS (EP/G032122/1).

\section{References}

[1] R. Abiev, S. Svetlov, S. Haase, Hydrodynamics and Mass Transfer of Gas-Liquid and Liquid-Liquid Taylor Flow in Microchannels, Chemical Engineering \& Technology 40 (2017) 1985-1998.

[2] D. Tsaoulidis, P. Angeli, Effect of channel size on liquid-liquid plug flow in small channels, AIChE Journal 62 (2016) 315-324.

[3] D. Tsaoulidis, V. Dore, P. Angeli, N.V. Plechkova, K.R. Seddon, Dioxouranium(VI) extraction in microchannels using ionic liquids, Chemical Engineering Journal 227 (2013) 151-157.

[4] D. Tsaoulidis, V. Dore, P. Angeli, N.V. Plechkova, K.R. Seddon, Extraction of dioxouranium(VI) in small channels using ionic liquids, Chemical Engineering Research Desing 91 (2013) 681-687.

[5] J. Jovanović, E.V. Rebrov, T. Nijhuis, M. Kreutzer, V. Hessel, J.C. Schouten, Liquid-liquid flow in a capillary microreactor: hydrodynamic flow patterns and extraction performance, Industrial \& Engineering Chemistry Research 51 (2011) 1015-1026.

[6] A. Tanimu, S. Jaenicke, K. Alhooshani, Heterogeneous catalysis in continuous flow microreactors: A review of methods and applications, Chemical Engineering Journal 327 (2017) 792-821.

[7] R.R. Soares, D.F. Silva, P. Fernandes, A.M. Azevedo, V. Chu, J.P. Conde, M.R. Aires-Barros, Miniaturization of aqueous two-phase extraction for biological applications: From micro-tubes to microchannels, Biotechnology Journal 11 (2016) 1498-1512.

[8] D. Tsaoulidis, V. Dore, P. Angeli, N.V. Plechkova, K.R. Seddon, Flow patterns and pressure drop of ionic liquid-water two-phase flows in microchannels, International Journal of Multiphase Flow 54 (2013) 1-10.

[9] A. Gupta, R. Kumar, Flow regime transition at high capillary numbers in a microfluidic T-junction: Viscosity contrast and geometry effect, Physics of Fluids (1994-present) 22 (2010) 122001. 
[10] D. Tsaoulidis, P. Angeli, Effect of channel size on mass transfer during liquid-liquid plug flow in small scale extractors, Chemical Engineering Journal 262 (2015) 785-793.

[11] M.N. Kashid, D.W. Agar, Hydrodynamics of liquid-liquid slug flow capillary microreactor: flow regimes, slug size and pressure drop, Chemical Engineering Journal 131 (2007) 1-13.

[12] N.D.M. Raimondi, L. Prat, Numerical study of the coupling between reaction and mass transfer for liquidliquid slug flow in square microchannels, AIChE Journal 57 (2011) 1719-1732.

[13] A. Woitalka, S. Kuhn, K.F. Jensen, Scalability of mass transfer in liquid-liquid flow, Chemical Engineering Science 116 (2014) 1-8.

[14] M. Darekar, N. Sen, K.K. Singh, S. Mukhopadhyay, K.T. Shenoy, S.K. Ghosh, Liquid-liquid extraction in microchannels with Zinc-D2EHPA system, Hydrometallurgy 144-145 (2014) 54-62.

[15] Q. Li, P. Angeli, Intensified Eu (III) extraction using ionic liquids in small channels, Chemical Engineering Science 143 (2016) 276-286.

[16] L.V. Resende, C.A. Morais, Study of the recovery of rare earth elements from computer monitor scrapsLeaching experiments, Minerals Engineering 23 (2010) 277-280.

[17] S. Cotton, Lanthanides and actinides, Macmillan International Higher Education1991.

[18] F. Xie, T.A. Zhang, D. Dreisinger, F. Doyle, A critical review on solvent extraction of rare earths from aqueous solutions, Minerals Engineering 56 (2014) 10-28.

[19] C.M. Leong, Y. Gai, S.K. Tang, Investigating droplet internal flow in concentrated emulsion when flowing in microchannel using micro-PIV, APS Meeting Abstracts, 2016.

[20] M. Raffel, C.E. Willert, F. Scarano, C.J. Kähler, S.T. Wereley, J. Kompenhans, Applications: Micro PIV, Particle Image Velocimetry, Springer 2018, pp. 547-584.

[21] F. Shen, Y. Li, Z. Liu, X. Li, Study of flow behaviors of droplet merging and splitting in microchannels using Micro-PIV measurement, Microfluidics and nanofluidics 21 (2017) 66.

[22] V. van Steijn, M.T. Kreutzer, C.R. Kleijn, $\mu$-PIV study of the formation of segmented flow in microfluidic Tjunctions, Chemical Engineering Science 62 (2007) 7505-7514.

[23] R. Matsumoto, H.F. Zadeh, P. Ehrhard, Quantitative measurement of depth-averaged concentration fields in microchannels by means of a fluorescence intensity method, Experiments in Fluids 39 (2005) 722-729.

[24] K. Shinohara, Y. Sugii, A. Hibara, M. Tokeshi, T. Kitamori, K. Okamoto, Rapid proton diffusion in microfluidic devices by means of micro-LIF technique, Experiments in Fluids 38 (2005) 117-122. 
[25] A. Riaud, S. Zhao, K. Wang, Y. Cheng, G. Luo, Lattice-Boltzmann method for the simulation of multiphase mass transfer and reaction of dilute species, Physical Review E 89 (2014) 053308.

[26] S. Zhao, A. Riaud, G. Luo, Y. Jin, Y. Cheng, Simulation of liquid mixing inside micro-droplets by a lattice Boltzmann method, Chemical Engineering Science 131 (2015) 118-128.

[27] L. Bai, S. Zhao, Y. Fu, Y. Cheng, Experimental study of mass transfer in water/ionic liquid microdroplet systems using micro-LIF technique, Chemical Engineering Journal 298 (2016) 281-290.

[28] V. Dore, D. Tsaoulidis, P. Angeli, Mixing patterns in water plugs during water/ionic liquid segmented flow in microchannels, Chemical Engineering Science 80 (2012) 334-341.

[29] L. Melby, N. Rose, E. Abramson, J. Caris, Synthesis and fluorescence of some trivalent lanthanide complexes, Journal of the American Chemical Society 86 (1964) 5117-5125.

[30] N.N. Li, Recent developments in separation science, (1972).

[31] M.B. Bogacki, Effect of various phenomena in the organic phase on metal extraction with chelating reagents in countercurrent and crosscurrent extraction systems, Industrial \& Engineering Chemistry Research 38 (1999) 1611-1617.

[32] W. Jiang, Y. Ma, W. Zhao, Y. Feng, N. Wang, Z.J.A. Si, b. chemistry, Determination of trace europium by use of the new fluorescence system europium-sparfloxacin-1, 10-phenanthroline-sodium dodecyl sulfate, Analytical and Bioanalytical Chemistry 377 (2003) 681-684.

[33] E. Roumpea, M. Chinaud, P. Angeli, Experimental investigations of non-Newtonian/Newtonian liquid-liquid flows in microchannels, AIChE Journal 63 (2017) 3599-3609.

[34] M.N. Kashid, I. Gerlach, S. Goetz, J. Franzke, J. Acker, F. Platte, D. Agar, S. Turek, Internal circulation within the liquid slugs of a liquid-liquid slug-flow capillary microreactor, Industrial \& engineering chemistry research 44 (2005) 5003-5010.

[35] D. Tsaoulidis, E.G. Ortega, P. Angeli, Intensified extraction of uranium (VI) in impinging-jets contactors, Chemical Engineering Journal (2018).

[36] M. Kashid, A. Gupta, A. Renken, L. Kiwi-Minsker, Numbering-up and mass transfer studies of liquid-liquid two-phase microstructured reactors, Chemical Engineering Journal 158 (2010) 233-240.

[37] J.-q. Liu, S.-w. Li, Y.-y. Wang, S. Jing, Extraction of uranium nitrate with $30 \%(\mathrm{v} / \mathrm{v})$ tributyl phosphate in kerosene in an pilot annular pulsed disc-and-doughnut column-Part I: Hydraulic performance, Solvent Extraction and Ion Exchange (2016). 
[38] N. Sen, M. Darekar, K. Singh, S. Mukhopadhyay, K. Shenoy, S. Ghosh, Solvent extraction and stripping studies in microchannels with TBP nitric acid system, Solvent Extraction and Ion Exchange 32 (2014) 281-300. [39] V.G. Lade, P.C. Wankhede, V.K. Rathod, Removal of tributyl phosphate from aqueous stream in a pilot scale combined air-lift mixer-settler unit: Process intensification studies, Chemical Engineering and Processing: Process Intensification 95 (2015) 72-79.

[40] B. Kadam, J. Joshi, S. Koganti, R. Patil, Hydrodynamic and mass transfer characteristics of annular centrifugal extractors, Chemical Engineering Research and Design 86 (2008) 233-244. 